\title{
ENTRE VERSOS, RIMAS E POESIAS: PERCURSOS DE ESCOLARIZAÇÃO E EXPERIÊNCIAS CORDELÍSTICAS DE POETAS POUCO ESCOLARIZADOS
}

\author{
July Rianna MeLo \\ AleXSANDRO SILVA \\ Universidade Federal de Pernambuco (UFPE), Recife, Pernambuco, \\ Brasil
}

\begin{abstract}
Resumo: Objetivamos investigar percursos de escolarização e experiências cordelísticas de três poetas pouco escolarizados, residentes no Agreste Pernambucano. Utilizamos a entrevista semiestruturada, cujos dados foram tratados à luz da análise temática de conteúdo. Os resultados evidenciaram que, no tocante aos percursos de escolarização, os cordelistas apresentavam relatos muito semelhantes, sobretudo no que se refere aos seus processos de alfabetização na instituição escolar. Os pais dos poetas não tiveram acesso à escola, e o cordel continuava sendo, para os entrevistados, o principal objeto de leitura. Além disso, o fato de os depoentes terem sido comerciantes de cordéis, quando jovens, teve um papel decisivo, tanto no conhecimento que eles tinham sobre o gênero discurso que produziam (no caso, o cordel) quanto na formação profissional como poeta.
\end{abstract}

Palavras-chave: Escolarização. Letramento. Cordel. Poetas.

INTRODUÇÃO

Nas últimas décadas, as discussões sobre os diferentes modos de apropriação da leitura e da escrita têm ganhado espaço nas produções acadêmicas brasileiras. As narrativas populares que remontam ao final do 
século XIX, por exemplo, colocaram homens e mulheres com baixas condições econômicas e pouca (ou nenhuma) escolarização na posição de ouvintes, leitores e produtores de textos. Mas se, até um período recente, apenas uma pequena parcela da elite cultural brasileira parecia ter um contato mais estreito com a escrita, podemos dizer que as relações entre os indivíduos das camadas populares e o universo da escrita nunca estiveram vinculadas estritamente à escola, pois inúmeras práticas educativas ocorreram (e têm ocorrido), no decurso da história, fora dessa instituição, principalmente para certos grupos sociais e em determinadas épocas (GALVÃO, 2001).

Dessa maneira, a formação do leitor e, também, do escritor não esteve (está) única e exclusivamente associada à escola e aos níveis de escolarização. Então, como pessoas que tiveram pouco acesso à escola, e de maneira bastante limitada, tornaram-se cordelistas? Que experiências de escolarização, ainda que restritas, tiveram esses poetas? Quais os percursos individuais desses sujeitos como escritores? Trazer à tona possíveis respostas para essas questões é o que pretendemos neste artigo.

Para Galvão (2006), a escolarização restrita, pelo menos na época do apogeu da literatura de cordel, não impedia que pessoas "analfabetas"1 tivessem acesso, lessem e/ou ouvissem os folhetos. Nessa direção, Soares (2014) explica que foi comumente atribuída à escola e à escolarização a função de assegurar aos indivíduos tanto a aprendizagem das habilidades básicas de leitura e escrita, isto é, a alfabetização, quanto o desenvolvimento das atitudes necessárias para o uso competente e efetivo da leitura e da escrita nas práticas sociais, ou seja, o letramento. Entretanto, essa mesma autora afirma que associar exclusivamente alfabetização à escolarização é desconsiderar que também se aprende a ler e a escrever em espaços não escolares, como a igreja, o trabalho e a família.

Tendo em vista o que expõe Soares (2014), podemos citar a tese de Oliveira (2015), que, ao analisar os significados da leitura e da escrita literária em camadas populares residentes no Morro do Papagaio, em Belo Horizonte - MG, constatou, a partir de um estudo de natureza etnográfica, que os três participantes da pesquisa (Luzia, 32 anos; Tatiana, 10 anos, e Matheus, 15 anos) apresentavam maneiras bastante singulares de se relacionar com a literatura em seu cotidiano e, além disso, a dinâmica intrafamiliar, as trajetórias escolares e outras instâncias socializadoras (como as práticas religiosas) influenciavam, diretamente, o modo como eles interagiam com o escrito.

Essa compreensão demonstra, no mínimo, que não há sempre uma relação proporcionalmente direta entre o grau de escolaridade e os níveis de letramento. Reconhecemos, ainda, que há certa dificuldade em se definir 
o letramento, por se tratar de um termo amplo e complexo. Segundo Soares (2009, p. 65), essas "[...] dificuldades e impossibilidades devem-se ao fato de que o letramento cobre uma vasta gama de conhecimentos, habilidades, capacidades, valores, usos e complexidades difíceis de serem contempladas em uma única definição". Concordamos também com Mortatti (2004) quanto ao fato de que, por se tratar de uma palavra recente, os significados que lhes são atribuídos nem sempre são idênticos, assim como os objetivos com que é empregada. Assumir esse pressuposto implica dizer que qualquer medição desse fenômeno será imprecisa, pois dependerá das habilidades de leitura e/ou escrita e/ou das práticas sociais de letramento que se estará avaliando, dos seus propósitos, do contexto e dos critérios utilizados.

Conforme Kleiman (1995), a escola preocupa-se com um tipo de prática de letramento, a alfabetização, concebida em termos de competências individuais, e não com o letramento como prática social. Por isso, corroboramos Street (2014) quanto à necessidade de rejeitar certas concepções que privilegiam uma forma particular de letramento, pois há múltiplos letramentos. No bojo dessa discussão, Soares (2002), ao discutir sobre o letramento na cibercultura, propõe o uso do termo letramentos, no plural, justamente para enfatizar que as diferentes tecnologias de escrita (tipográficas e digitais) gerariam diferentes estados ou condições naqueles que delas fazem uso, resultando em diferentes letramentos.

Neste artigo, ancorados nas discussões teóricas, apresentamos parte dos resultados de estudo que desenvolvemos com o objetivo de investigar percursos de escolarização e experiências cordelísticas de três poetas pouco escolarizados, residentes no Agreste Pernambucano.

\section{CORDEL: PRODUTORES, LEITORES E OUVINTES}

O termo cordel, até o final da década de 1960, não era uma expressão usualmente utilizada para designar esse gênero poético. O epíteto "literatura de cordel" foi dado aos folhetos brasileiros, pelos estudiosos, como uma forma de atribuir uma gênese portuguesa a essa forma de poesia impressa, produzida e consumida no Brasil (GALVÃO, 2000). Embora várias pesquisas tenham apontado que a origem dos folhetos seja ibérica, o estudo conduzido por Abreu (1993) evidenciou que a literatura de cordel portuguesa, apesar de ter exercido alguma influência nos folhetos nordestinos, não constituiu a matriz a partir da qual esse tipo de literatura se desenvolveu no contexto brasileiro, pois os poetas nordestinos introduziram significativas alterações nos enredos e, principalmente, nas formas de composição. 
Para Abreu (2006) e Terra (1983), é desde o final do século XIX e início do século XX, mais precisamente na década de 1920, que se começam a definir as características formais dessa literatura. É nesse período também que se estabelece no Brasil o processo de edição, comercialização e formação do público leitor/ouvinte dos cordéis. Apesar de o início da publicação mais sistemática dos folhetos nordestinos ser atribuído ao poeta Leandro Gomes de Barros, no século XIX, é somente no começo do século seguinte que o poeta e editor João Martins de Athayde introduz inovações na impressão dos folhetos. Cabe acrescentar que, por meio desses poetas, foram fixadas as regras de criação poética (rima, métrica e oração) e de impressão (GALVÃO, 2006).

Galvão (2002), em um artigo elaborado com base nos resultados da sua pesquisa de doutorado, observou que o fato de os folhetos serem lidos de maneira coletiva e estarem, direta ou indiretamente, ligados à tradição oral os tornava mais próximos daqueles que apresentavam pouca familiaridade com o universo da escrita. Como estavam diretamente relacionados à oralidade, não surpreende que os principais palcos dos cordéis tenham sido as feiras, tão comuns no interior brasileiro, onde seus autores - também chamados de cordelistas ou poetas de bancada (GALVÃO, 2000) - declamavam seus versos para uma variada plateia, formada de crianças a idosos, de compradores a feirantes.

Estudiosos como Arantes (1982) e Abreu (1997) apontaram que as trajetórias dos cordelistas eram bastante semelhantes, sobretudo até a década de 1960: muitos deles nasceram no campo e eram filhos de pequenos proprietários ou de trabalhadores assalariados; apresentavam pouca ou nenhuma escolarização, embora vários fossem autodidatas ou tivessem aprendido a ler com familiares e conhecidos; o aprendizado formal, em escolas, era pouco frequente, e a escolarização não era um requisito fundamental para o sucesso na carreira como cordelista, ainda que fosse necessário o contato com alguns dos conteúdos da tradição letrada (ABREU, 1997).

Nessa direção, corroboramos a ideia de Galvão (2006) de que não se pode associar o gênero a certo perfil de leitor ou, ainda, a uma camada social e a uma cultura específicas. O que é preciso reconhecer, em conformidade com Abreu (1993, p.173), é que, embora grande parte do público leitor/ouvinte desse gênero pertencesse predominantemente às classes populares, alguns setores das classes dominantes"interessavam-se pelos folhetos, pois, apesar das diferenças econômicas, estavam também imersos numa cultura oral e tinham como uma das principais fontes de lazer as histórias narradas nos folhetos".

Resende (2010), ao entrevistar poetas e editores entre 2002 e 2004, esclarece que houve um distanciamento desses poetas do quadro de pouca 
escolarização que os caracterizava no período tradicional. Essas mudanças, consoante a autora, não podem, de modo algum, estarem dissociadas da enorme expansão da escolarização e do acesso à universidade, sobretudo no final do século XX. Não é difícil, portanto, perceber que o perfil dos cordelistas e dos leitores já não é mais o mesmo de épocas passadas.

Nas últimas décadas, a produção e a difusão dos impressos, que antes demandavam dos poetas o deslocamento até as tipografias e as feiras, foram sendo acrescidas da possibilidade de composição gráfica, impressão e montagem dos folhetos por meio do computador, sem a necessidade de se mover para outros espaços físicos (AMORIM, 2009). Nesse sentido, podemos dizer que as imagens, os temas e os estilos do cordel são situados histórica e socialmente e, à vista disso, estão suscetíveis às mudanças. Essas modificações são, também, resultado das estratégias de permanência do gênero, que se adapta a novas configurações. Cabe salientar, porém, que não se trata de uma evolução linear, pois esses diferentes formatos podem ter coexistido ao longo da história do cordel, tendo sido abandonados e retomados em função das necessidades sociais.

Por essa razão, importa salientar que, apesar dos prenúncios de morte do cordel, em torno dos últimos dois decênios, os folhetos passaram a ser impressos em computador, na própria residência dos poetas, e divulgados através da internet, conquistando, até mesmo, outros suportes de circulação e divulgação (AMORIM, 2009). Os folhetos também deixaram de ser, há muito tempo, produzidos unicamente no Nordeste brasileiro. Com a migração dos poetas e editores, os cordéis ultrapassaram os limites dessa região, sedimentando-se em diversos locais.

\section{O ESTUDO DESENVOLVIDO E OS SEUS CAMINHOS METODOLÓGICOS}

Para atender ao objetivo geral deste estudo, apoiamo-nos em uma abordagem qualitativa, uma vez que buscamos dar possíveis respostas a questões particularistas, captando, muitas vezes, o que estava nas entrelinhas, para assim enxergarmos a realidade em toda sua dinamicidade (MINAYO; SANCHES, 1993).

Para participar dessa pesquisa, selecionamos três poetas, em função, sobretudo, de seu nível de escolaridade ${ }^{2}$ e das idades/pertencimento geracional, conforme detalharemos a seguir. Neste trabalho, mantivemos os nomes originais dos depoentes por opção deles e em conformidade com o Termo de Consentimento Livre e Esclarecido que todos assinaram. No Quadro 1 , podemos observar algumas informações sobre o perfil dos entrevistados. 
Quadro 1 - Perfil dos poetas participantes da pesquisa

\begin{tabular}{|c|c|c|c|}
\hline \multicolumn{4}{|c|}{ Entrevistados } \\
\hline Nome & $\begin{array}{c}\text { José Francisco } \\
\text { Borges } \\
\text { (J. Borges) }\end{array}$ & $\begin{array}{c}\text { Paulo Pereira da } \\
\text { Silva } \\
\text { (Paulo Pereira) }\end{array}$ & $\begin{array}{c}\text { José Manuel dos } \\
\text { Santos } \\
\text { (Zé Guri) }\end{array}$ \\
\hline Idade & 80 anos & 71 anos & 66 anos \\
\hline $\begin{array}{c}\text { Ano de } \\
\text { nascimento }\end{array}$ & 1935 & 1945 & 1950 \\
\hline $\begin{array}{l}\text { Cidade na } \\
\text { qual reside } \\
\text { atualmente }\end{array}$ & Bezerros - PE & Caruaru - PE & Belo Jardim - PE \\
\hline $\begin{array}{l}\text { Residência } \\
\text { anterior }\end{array}$ & $\begin{array}{c}\text { Sítio } \\
\text { Bezerros }\end{array}$ & $\begin{array}{l}\text { Sítio } \\
\text { Lajedo }\end{array}$ & $\begin{array}{c}\text { Sítio } \\
\text { Belo Jardim }\end{array}$ \\
\hline Ocupação atual & $\begin{array}{c}\text { Comercializa cordéis, } \\
\text { mas tem atuado, } \\
\text { sobretudo, como } \\
\text { xilógrafo }\end{array}$ & $\begin{array}{l}\text { Comerciante } \\
\text { aposentado }\end{array}$ & $\begin{array}{c}\text { Comercializa } \\
\text { cordéis e outros } \\
\text { objetos (CDs, } \\
\text { chapéus, espelhos e } \\
\text { outros) }\end{array}$ \\
\hline Escolaridade & $\begin{array}{l}\text { Um ano incompleto } \\
\text { (10 meses) }\end{array}$ & $\begin{array}{l}\text { Terceira série do } \\
\text { Ensino Fundamental }\end{array}$ & Um ano incompleto \\
\hline $\begin{array}{l}\text { Escolaridade } \\
\text { dos pais }\end{array}$ & $\begin{array}{c}\text { Não frequentaram a } \\
\text { escola } \\
\text { (o pai sabia ler e } \\
\text { escrever) }\end{array}$ & $\begin{array}{c}\text { Não frequentaram a } \\
\text { escola }\end{array}$ & $\begin{array}{c}\text { Não frequentaram } \\
\text { a escola }\end{array}$ \\
\hline $\begin{array}{l}\text { Ocupação dos } \\
\text { pais }\end{array}$ & $\begin{array}{l}\text { Agricultores e } \\
\text { almocreve }^{3}\end{array}$ & Agricultores & Agricultores \\
\hline
\end{tabular}

Fonte: Os autores (2017).

Ao observarmos detidamente o Quadro 1, averiguamos que os participantes, apesar de apresentarem idades distintas, compartilhavam certo pertencimento geracional, pois nasceram entre os anos de 1935 e 1950. Na época da pesquisa, eles residiam em cidades localizadas na microrregião do Agreste Pernambucano, ainda que tenham sido oriundos de áreas rurais e, mais tarde, se deslocado para os centros urbanos.

Quanto à escolaridade e à ocupação dos entrevistados, percebemos que tiveram pouco acesso à escola (no máximo, três anos) e atuavam (ou atuaram), sobretudo, como comerciantes. Os pais dos cordelistas trabalhavam como agricultores e não haviam frequentado a escola. Segundo Márcia Abreu (1997), este é um dado recorrente nas pesquisas que envolvem 
cordelistas, pois muitos deles são filhos de pequenos proprietários ou de trabalhadores assalariados, oriundos da área rural. Pode-se dizer, também, que isso acontece porque, até a metade do século XX, em 1950, apenas 34,4\% dos pernambucanos residiam em áreas urbanas estaduais, pois foi apenas em 1970, de acordo com o censo demográfico, que a população urbana se tornou superior à rural.

No que concerne aos procedimentos metodológicos adotados, realizamos entrevistas semiestruturadas, que consistiam em uma série de perguntas verbais abertas, em uma ordem prevista, na qual o entrevistador acrescentava perguntas de esclarecimento (LAVILLE; DIONE, 1999). Todas as entrevistas foram feitas na residência dos entrevistados ou na Academia Caruaruense de Literatura de Cordel, no período de agosto a outubro de 2016, conforme a disponibilidade dos poetas. Para registros dos dados, utilizamos como auxílio a gravação de áudio. Não buscamos desenvolver um estudo minucioso sobre as trajetórias familiares e de escolarização dos entrevistados, mas, sim, entender, brevemente, como as suas experiências escolares e extraescolares poderiam se relacionar às suas carreiras como cordelistas. Considerando essa ressalva, apresentamos aos poetas um conjunto de perguntas sobre suas experiências escolares e sobre suas vivências como cordelistas, de modo a termos acesso a informações sobre a pouca escolarização que tiveram e como ocorreram os primeiros contatos deles com o gênero cordel, como produziam e de que modo o faziam.

Os dados gerados a partir desse procedimento metodológico foram tratados a partir da análise de conteúdo (BARDIN, 1979), que foi desenvolvida por temas (análise temática categorial) e envolveu as seguintes etapas: préanálise, análise do material (codificação e categorização da informação), tratamento dos resultados, inferência e interpretação. Após dispormos do material gerado a partir das entrevistas, fizemos uma leitura flutuante do texto, que fora antes devidamente transcrito, com o objetivo de ter as primeiras impressões sobre os dados. Em seguida, construímos categorias de análise, as quais consideraram as regras de exaustividade, representatividade, homogeneidade e pertinência.

O QUE NOS DIZEM OS POETAS SOBRE OS SEUS PERCURSOS DE ESCOLARIZAÇÃO?

Embora, hoje, a educação constitua um direito no decorrer da história, ela foi um privilégio de poucos. De acordo com o cordelista J. Borges, durante os anos 1940, era difícil os povos campesinos terem acesso à escola. Segundo os dados do Instituto Brasileiro de Geografia e Estatística, doravante IBGE, em 
1944, havia, em todo o estado de Pernambuco, apenas 853 unidades escolares localizadas no campo que ofertavam o ensino fundamental ${ }^{4}$.

No tempo que eu me criei lá no sítio não existia escola lá. Só tinha escola aqui em Bezerros [área urbana] ou lá em Gravatá [cidade vizinha]. Mas era uns vinte e tantos quilômetros para Gravatá e para aqui [se referindo à cidade de Bezerros] era dezesseis quilômetros. Então, eu não tinha condição de vir a pé para escola. Então, fiquei até os doze anos doido pra escrever meu nome, mas não tinha condição. Um dia, um rapaz inventou uma escolinha particular lá e meu pai falou com ele. Eu fui pra escola, passei dez meses e com dez meses o irmão dele, que já trabalhava em Recife, arranjou um emprego, e ele foi embora. Fiquei sem escola (J. Borges).

Para Silva (2003), até as primeiras décadas do século XX, a escola no campo surge de forma tardia e destinada apenas a uma minoria da população. Ainda que, nesse período, o Brasil se constituísse como um país predominantemente agrário, as especificidades da cultura local eram desconsideradas. Conforme Zé Guri, era necessário que os pais pagassem aulas particulares a professores, que residiam em cidades circunvizinhas, para que os filhos aprendessem a ler e escrever, sem que fosse preciso se deslocar para os centros urbanos. À vista disso, destacou o poeta:

Lá no sítio, lá na época, não tinha nem escola. Eu passei uma temporadazinha na escola particular com papai pagando ao professor que veio de Lajedo [cidade da região] na época. Aí, eu passei pouco tempo e não tinha quase escola do município, não (Zé Guri).

A escola nessa época não era graduada por séries, e os alunos eram agrupados pelo nível de instrução que apresentavam. Assim,"naquele tempo, não tinha nem quase nome de série. A gente começava na carta de $A B C$, cartilha e o primeiro livro, somente. Não tinha esse negócio de fazer prova e nem arranjar boletim. Li só até o primeiro livro e bem pouquinho", ressaltou Zé Guri, durante a entrevista. Nessa direção, Galvão e Batista (1998, p.25) afirmam que, no início do século XX, "o professor não dava aulas, como hoje estamos acostumados a pensar, mas 'tomava' a lição de cada um dos alunos, fazendo-os ler em voz alta. Enquanto isso, os outros alunos ficavam em suas carteiras lendo a lição do dia".

Apesar de o movimento da Escola Nova, emergido na década de 1930, ter criticado assiduamente o uso dos castigos como forma de condenar o mau comportamento e as dificuldades de aprendizagem, as práticas punitivas, na década de 1940, ainda eram empregadas na maioria dos espaços escolares. Essa afirmação encontrou eco nos dizeres de J. Borges: 
[...] Primeiro, a gente fazia uma escrita, copiava numa folha de caderno, depois fazia uma conta de dez colunas (uma conta de somar), somava e escrevia por extenso o resultado (um milhão trezentos e vinte e oito cruzeiros e vinte e cinco centavos). Tinha que escrever por extenso ali embaixo. Se não lesse, se fizesse a conta e não lesse o resultado, era meia dúzia de "bolo" que levava. Então, eu nunca apanhei, não por conta disso, mas tinha menino que vinha com a mão inchada. [...] De qualquer modo, eu apanhava "bolo" também, porque o professor perguntava uma pergunta fácil, eu ganhava. Agora, quando era mais difícil, aqui acolá, eu errava. Mas, só quem dava em mim era o professor, porque o professor dava um "bolinho" bom e os outros, quando davam, era para estourar as mãos. Aí, era proibido passar da orelha à palmatória. A palmatória era uma bola de madeira com um cabinho feito uma colher de pau e aí não podia passar da orelha. Quando passava da orelha, o professor pegava e dizia: “Olhe, eu disse a você que não pode passar da orelha". E "Pá!", dava um "bolo" (J. Borges).

No Brasil, a palmatória foi um dos instrumentos de punição mais utilizados pelos professores no século XIX e em grande parte do século XX (MORAES; SANTOS, 2009), sendo introduzida no país pelos jesuítas como forma de disciplinar os índios. De maneira semelhante a J. Borges, o cordelista Paulo Pereira lembrou-se do uso intensivo da punição, que tanto aterrorizava os alunos e norteava a ação escolar.

Nós tínhamos tanto medo do professor que bastava ele falar. Ele ensinava a gente a soletrar. Vê como era que ele ensinava: RATOEIRA. Ele fazia: $R \hat{E}+A=R A$ (ele puxava muito pelo " ${ }^{\prime \prime}$ ) $|\mathrm{T}+\mathrm{O}=\mathbf{T O}| \mathrm{E}+\mathrm{I}=\mathrm{EI}|\mathrm{RE}+\mathrm{A}=\mathbf{R A ́}| \mathbf{R A T O E I R A}$. Entendeu? Aí, tudo dele era soletrar. Ele fazia uma tábua com um buraco. Então, ele saia colocando em cima das letras que era pra você sair conhecendo o alfabeto. Ele botava a taboa aqui e perguntava: "Que letra é essa?" Que era pra você aprender as letras, porque você vai escrever o nome. Muitas vezes, você vai escrever o nome, mas não bota o nome completo. Você pensa que tá certo, mas se você for naquele negócio (soletrando) está errado. Num passou na televisão um dia desse esse soletrando que até o garotinho ganhou 40 mil? A gente que soletra, a gente não erra, porque já tem aquele negócio na mente. Tá certo, eu escrevo errado porque meu estudo é pouco, mas conto as letras que tem naquela palavra. Olhe, ele tinha um nome que não existe esse nome, que era pra você aprender a soletrar. Você já viu o nome com cinco " $\mathrm{H}$ "? Tá vendo? Ele fazia isso. Ele inventou esse nome, porque era pra gente aprender a soletrar. Pra você ver se vai saber que nome é esse: $\mathrm{P}-\mathrm{H}-\mathrm{O}-\mathrm{PON} / \mathrm{T}-$ H-TA/D-H-I-DI/L-H-I-LHI/N-H-A-NHA. Que nome é esse? É PONTA DE LINHA. Ponta de linha não é escrita assim, mas ele fazia assim pra você aprender a soletrar chamando a letra toda. PONTA DE LINHA (P-H-O-PON-T-H-TA-D-H-I-DI-L-H-I-LHI-N-H-A-NHA). Tá entendendo como era? Pronto, a gente tinha 
medo e através do medo era que a gente aprendia. A gente lia o primeiro livro, depois, no próximo ano, ia recordar o mesmo livro (Paulo Pereira).

Como podemos observar no depoimento de Paulo Pereira, o professor utilizava o método da soletração/deletreação, que faz parte do grupo de métodos sintéticos, segundo o qual se deveriam aprender, primeiramente, as unidades menores da língua (letra; fonema; sílaba) para, posteriormente, aprender as unidades maiores (palavra; frase; texto). Deverse-ia, assim, o ensino da leitura iniciar com a apresentação das letras e seus respectivos nomes para que, subsequentemente, os alunos conseguissem reunir as letras formando sílabas, conhecer as famílias silábicas, ler palavras formadas por essas sílabas e letras e, por fim, formar frases (MORTATTI, 2006). Segundo Frade (2014), as sílabas eram aprendidas como uma sequência de letras soletradas e, em decorrência da falta de sentido, era comum colocar os alunos para cantarem as combinações (o que era nomeado de cantilena):

Eu ia buscar o leite do meu irmão, aí passava em frente da escola. Aí, estavam os meninos dizendo: B-A|BA, B-E|BE, B-I|BI, B-O|BO,B-U| BU, B-ÃO|BÃO (BA-BE-BI-BO-BU-BÃO). Era esse negócio assim. Quando eu peguei a carta do $\mathrm{ABC}$, aí comecei o "A" e tal, o maiúsculo, o minúsculo e passei pra cartilha, da cartilha pra o primeiro livro e pronto (Zé Guri).

No entanto, evidenciamos que, apesar de esses poetas terem frequentado a escola, ainda que de maneira limitada e por um tempo bastante curto, a aprendizagem da leitura e escrita era atribuída, por todos eles, ao contato que tiveram com cordéis ao longo dos anos e não ao breve processo de escolarização que tiveram.

O cordel, portanto, para além dos fins de comercialização, desempenhava um papel fundamental na alfabetização desses poetas. Logo, podia-se dizer que, em muitas situações, "o 'alfabetizando', em um processo solitário de reconhecimento das palavras e versos, procedia, ele mesmo, à decodificação. Aos poucos, esse processo se ia estendendo a outros objetos de leitura" (GALVÃO, 2000, p. 498).

Depois, eu comecei vender cordel e do cordel eu aprendi muita coisa. Porque o cordel é uma miscelânea que tem de tudo e todos os assuntos têm no cordel. Então, eu ampliei mais a minha letra, a minha leitura. A ortografia eu melhorei muito depois do cordel (J. Borges).

Em conformidade com o que apontamos anteriormente, os percursos dos poetas eram bastante semelhantes, sobretudo até o início do século XX: muitos deles nasceram no campo e eram filhos de pequenos 
proprietários ou de trabalhadores assalariados e apresentavam pouca ou nenhuma escolarização e, não muito raramente, aprenderam a ler a partir da audição dos folhetos, tratando-se de autodidatas (ABREU, 1997). Os pais dos depoentes não chegaram a frequentar a escola, tal como exposto no extrato do depoimento que segue:

Um deles não sabia nem a letra "A". Parece que eles nunca entraram numa escola, nem papai, nem mamãe. Eu ainda fui pra escola no sítio, tentei na cidade ir lá ao colégio, mas não teve jeito não. Eu digo que não aprendi nada na escola. O que eu aprendi foi no cordel e até agora eu digo que sei ler até muito porque todos os dias eu leio um livro, leio uma carta, leio revista, leio cordel, leio a bíblia, leio tudo. Eu sei ler (Zé Guri).

Por meio das narrativas acerca das experiências de escolarização dos poetas, observamos que eles apresentaram relatos muito semelhantes, principalmente no que diz respeito às práticas educativas a que tiveram acesso e às relações que, de uma maneira ou de outra, tinham com a escola.

OS PRIMEIROS PASSOS PARA TORNAREM-SE CORDELISTAS: MEMÓRIAS SOBRE O FAZER POÉTICO

Todos os cordelistas entrevistados iniciaram as suas carreiras como folheteiros. Foi, portanto, a partir desse primeiro contato como vendedores ambulantes que os entrevistados se lançaram, mais tardiamente, como poetas. Arantes (1982), ao investigar a produção de cordéis no Nordeste, na década de 1970, também evidenciou que, a partir da comercialização desse material impresso, os poetas passaram a relacionar-se mais diretamente com os editores e, através da leitura dos cordéis nas feiras, tinham a oportunidade de desenvolver, gradualmente, o domínio sobre a forma de linguagem própria do gênero. A respeito do assunto, Zé Guri exprimiu como ocorreu o seu primeiro contato com o cordel:

[...] Eu carregava a mala de livro para todo canto que eu ia. Eu carregava a viola de um lado, o pandeiro em uma pasta e a mala de livro do outro lado. Porque quando eu chegava na feira que tinha um cantador de viola, nós fazia cantoria; se chegasse a outra feira que tivesse um coquista [nome dado aos cantadores de coco], nós fazia embolada; e quando não tinha ninguém eu ia vender folheto sozinho. Aí, de todo o jeito eu aproveitava o tempo e o trabalho. Eu pegava o cordel, comprava e saía cantando na feira fazendo a propaganda (Zé Guri). 
Como evidenciamos no depoimento acima, antes de ser produtor de folhetos, Zé Guri já era repentista e embolador. Há, portanto, repentistas e emboladores que são também cordelistas, e vice-versa, mas isto não é uma regra. Vários dos poetas entrevistados referiam-se, com certa frequência, aos gêneros repente e embolada. A literatura de cordel, ainda que impressa, mantém uma estreita relação com a música. Para Ayala (2010), isso é compreensível porque, embora o cordel tenha a escrita como base de criação, ele mantém vínculos com os sistemas que se alicerçam na oralidade, não apenas por ser cantado ou declamado, mas por ter trazido o repente e a embolada para o interior da composição escrita.

Reconhecemos que, apesar de os gêneros discursivos cordel, repente e embolada apresentarem semelhanças no que concerne a seus aspectos formais (rima, métrica e oração) e estarem intimamente relacionados em sua história e prática, eles são distintos (SAUTCHUK, 2009). O cordel trata-se de um gênero de composição escrita, embora possa ser oral no que diz respeito à sua transmissão e à sua fruição. Já o repente ou cantoria é um gênero poético-musical improvisado, no qual, geralmente, os repentistas, com o auxílio da viola, apresentam-se em dupla, alternando-se na criação das estrofes. Essa relação entre os cantadores, como enfatiza Sautchuk (2009), pode ser caracterizada tanto pela disputa quanto, também, pela parceria. A embolada é um gênero bastante confundido com a cantoria, contudo, o desafio poético entre os dois poetas é acompanhado pelo som do pandeiro ou ganzá.

Além disso, notamos, por meio da declaração de Zé Guri, que, para tornar-se folheteiro, era necessário saber cantar ou declamar os folhetos publicamente. Os poetas, sobretudo os mais velhos, costumavam usar

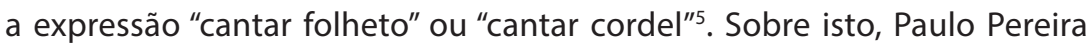
comentou:

Olhe, na minha infância, eu já cantava cordel. Eu ganhava dois mil réis pra cantar cordel, porque eu canto cordel. O cordel cantado ele é mais bonito. Você lê, tá certo, mas você vai cantar o cordel chama atenção. Entendeu como é? Esse cordel da caveira e o viajante eu coloquei uma melodia nele que é uma melodia bonita pra cantar. Se for o cordel em embolada eu canto ele no ritmo de embolada, se for de forró, se for de canção, se for de aboio, do que ele for publicado, eu canto. Se for uma história triste, eu coloco uma melodia triste, se for uma história alegre, eu coloco uma melodia alegre (Paulo Pereira).

Esse canto dos folhetos, como explica Arantes (1982), era sempre acompanhado de breves explicações ou comentários sobre os enredos, chamando-se, dessa maneira, a atenção dos ouvintes para as histórias 
narradas pelos vendedores. Esse autor, como base nos dados de sua pesquisa realizada nos anos 1970, enfatiza que os folheteiros costumavam chegar cedo à feira para montar sua "banca". Geralmente, colocavam os cordéis em uma maleta que ficava exposta sob uma armação de madeira, abriam o guardasol, levantavam o tripé do alto-falante, quando o possuíam, e começavam a trabalhar. É o que, também, esclareceu o poeta J. Borges:

Uma vez, lá em Caruaru, quando a feira era lá perto da Estação, coloquei o carro perto de um pé de árvore bem grande num dia de terça-feira. Aí, amarrei o alto-falante lá em cima das folhas do mato, com a boca pra baixo, montei a banca e larguei o pau (pá-pá-pá). Aí, quando cercou de gente na sombra, aí eu li essa história d"'Os olhos de dois amantes por cima da sepultura", de Cícero Vieira da Silva. Naquele tempo, o povo tinha tempo e ficava lá duas, três horas esperando. Eu vendi 50 romances nessa lida. Por que a história é muito emocionante, sabe? (J. Borges).

As estratégias de comunicação das narrativas pelos folheteiros não se restringiam apenas à oralização dos folhetos, mas envolviam também uma expressão corporal que se manifestava através dos movimentos das mãos e da curvatura do corpo, ao compasso mesmo dos versos (MATOS, 2007). Segundo Galvão (2006), a performance do folheteiro parecia constituir um dos fatores mais importantes para a definição de quais folhetos comprar por parte dos leitores/ouvintes por ela entrevistados, sobretudo para aqueles com menor nível de letramento. A leitura dos versos era sempre interrompida pelo folheteiro no momento clímax da história. O uso dessa estratégia (chamada de tranca) empregada na venda dos folhetos foi assim referenciado por Borges:

Eu tenho a história “Domiciano e Rosete ou viajante da sorte". O pai de Domiciano perdeu-se e ele saiu procurando o pai dele. Andou o dia todo, parou em uma fazenda, pediu arrancho ao fazendeiro pra dormir lá e disse que estava procurando o pai dele. Era naquele tempo que ninguém tinha maldade e a pessoa dormia na casa de estranhos. Aí, deram o arrancho a ele e de noite na hora da janta, que na época se chamava ceia, a filha do fazendeiro foi servir a mesa. Ele olhou pra ela assim, ela olhou também e acabaram simpatizando um com o outro. No fim, o fazendeiro disse: "Fulana, vá preparar a cama para o rapaz". Ela foi lá pro quarto, forrou a cama, perfumou, depois fez um bilhete e botou em cima do travesseiro, um bilhete dizendo: "Rapaz estranho e bonito, eu quero falar com você". Aí, pronto, ele leu o bilhete e no outro dia não viajou, ficou por ali. O velho gostava muito dele. Teve uma noite que a filha do fazendeiro foi dormir com ele. Eu pensando como era que o povo ia gostar da história, revelei o segredo para o velho, na história, dizendo que ele ouviu a cama ranger. Aí, o povo gostava tanto dessa história que depois eles procuravam: "Seu Zé, o senhor tem aquele folheto que diz a 
cama rangendo?" Eu disse: "Tem". Todo mundo achava engraçado quando ia ler. Quando dizia "o velho viu a cama ranger", aí eu parava. Parava e nós chamava de "Tranca". Dava o "tranca" e o povo dizia: "Vá, leia logo que é pra a gente ver". Eu dizia: "Não, eu vou vender logo um aqui, outro ali, outro acolá, a senhora também leva um, o senhor leva um e eu vou terminar". O cara disse: "Eu vou levar, mas só vou levar se você ler o resto pra eu ver como foi a confusão" (J. Borges).

Poder acompanhar a reação dos ouvintes no transcorrer das histórias permitia que os vendedores identificassem aquelas narrativas que melhor agradavam os compradores, o que, possivelmente, os influenciava no momento de compor uma nova história (ABREU, 2006).

Além das feiras, os folhetos costumavam ser lidos/cantados nas próprias residências dos poetas ou familiares, onde, geralmente, as pessoas reuniam-se em grupos para declamá-los/lê-los, conforme também atestado por Galvão (2000). Nessas situações de leitura coletiva dos cordéis, Arantes (1982) informa que as pessoas tentavam reproduzir em casa o modo de leitura realizada pelo folheteiro. J. Borges, ao se referir às situações de leitura e audição de folhetos, acrescentou:

A gente não tinha acesso a livro, jornal, não existia televisão nos anos 40. Já tinha a Rádio Clube e a Rádio Jornal, mas só quem possuía rádio era rico. Aqui ou acolá, tinha um fazendeiro que tinha um rádio de bateria que levava pra carregar, no sábado, na cidade e usava o rádio só durante a semana, mas a gente não tinha nem o direito de chegar na porta. Então, não tinha informação nenhuma e aonde tinha informação era o cordel que era lido nas bocas de noite, nos feriados, nos sábados e domingos. Meu pai gostava muito de ler cordel. Toda noite ele lia um, dois e eu ficava na mesa escutando e ali mesmo eu cochilava, dormia. E eu me apaixonei. Quando eu cheguei, nos vinte anos, comecei a trabalhar com cordel e até hoje (J. Borges).

Nas primeiras décadas do século $X X$, o jornal ainda não estava acessível à grande parcela da população e o rádio ainda se encontrava em processo de expansão. A leitura/audição dos folhetos era a principal forma de diversão, lazer e informação. Com efeito, os chamados "folhetos de acontecido" ou "folhetos circunstanciais", que divulgavam as notícias diariamente em nível local, nacional e internacional, eram considerados os "jornais do povo". Até mesmo naqueles lugares onde se dispunha do rádio, os folhetos ainda tinham um importante papel informativo (GALVÃO, 2006). Percebemos a pertinência desta colocação quando observamos o relato de Paulo Pereira: 
O cordel é o jornal do povo. Na época que o cordel surgiu não existia a tecnologia que existe hoje. Então, quando acontecia um fato, se fazia um apanhando de tudo aquilo ali, do dia, da hora que aconteceu, os personagens que estavam envolvidos naquele problema, tudo para poder se escrever um cordel. [...] Tá certo que a gente faz um cordel de brincadeira, como um homem casando com uma jumenta ou uma mulher sem cabeça correndo pelo meio da rua. Isso tudo é pra brincadeira, mas quando são fatos reais a gente tem que fazer do jeito que aconteceu, porque esse é o jornal do povo (Paulo Pereira).

Ate hoje, para Zé Guri, o rádio também desempenha um papel fundamental, sobretudo porque na cidade em que reside existem várias rádios em funcionamento, dentre as quais podemos destacar a Rádio Belo Jardim (104.9FM), a Rádio Bitury (153.0 AM) e a Rádio Itacaité (88.1 FM), o que demonstra, portanto, a força de uma oralidade secundária.

\section{CONSIDERAÇÕES FINAIS}

Ao investigar os percursos de escolarização e as experiências cordelísticas de três poetas pouco escolarizados, residentes no Agreste Pernambucano, vimos que os entrevistados apresentavam memórias muito semelhantes do período de escolarização que tiveram, provavelmente porque compartilhavam, dentre outros aspectos, um pertencimento geracional e geográfico, o que os situava em um grupo com uma série de experiências comuns. Além disso, o fato de terem sido comerciantes de cordéis, quando jovens, parece ter tido um papel decisivo, tanto no conhecimento que eles tinham sobre o gênero discurso que produziam (no caso, o cordel) quanto na formação profissional como poeta.

Os entrevistados pareceram construir seus conhecimentos sobre o sistema de escrita alfabética principalmente em situações de letramentos, ou seja, por meio da interação com materiais escritos (sobretudo com o cordel) e da participação em práticas sociais de leitura e de escrita ou mediadas pela escrita. Mesmo sendo pertencentes a grupos denominados"improváveis" (que não dispunham de condições familiares favoráveis para o uso da leitura e da escrita), tornaram-se poetas e demonstravam vivenciar, de forma autônoma, práticas significativas de letramento. 


\section{BETWEEN VERSES, RIMS AND POETRIES: SCHOOLING TRAILS AND CORDELISTIC EXPERIENCES OF POOR SCHOOL POETS}

ABSTRACT: We aim to investigate schooling and cordelistic experiences of three poorly schooled poets, living in Agreste Pernambucano. We used the semi-structured interview, whose data were treated in light of the thematic content analysis. The results showed that, in relation to the schooling trajectories, the cordelistas had very similar reports, especially regarding their literacy processes in the school institution. The parents of the poets did not have access to the school and the cordel remained the main object of reading for the interviewees. Moreover, the fact that the deponents were string merchants as young men played a decisive role both in their knowledge of the discourse genre they produced (in this case, the cordel) and in professional training as a poet.

KEYWORDS: Schooling. Literacy. Cordel. Poets.

\section{ENTRE VERSOS, RIMASY POESIAS:PERCURSOS DE ESCOLARIZACIÓNY EXPERIENCIAS CORDELÍSTICAS DE POETAS POCO ESCOLARIZADOS}

RESUMEN: Objetivamos investigar itinerarios de escolarización y experiencias cordelísticas de tres poetas poco escolarizados, residentes en el Agreste Pernambucano. Utilizamos la entrevista semiestructurada, cuyos datos fueron tratados a la luz del análisis temático de contenido. Los resultados evidenciaron que, en cuanto a los recorridos de escolarización, los cordelistas presentaban relatos muy semejantes, sobre todo en lo que se refiere a sus procesos de alfabetización en la institución escolar. Los padres de los poetas no tuvieron acceso a la escuela y el cordel seguía siendo, para los entrevistados, el principal objeto de lectura. Además, el hecho de que los exponentes fueran comerciantes de cordeles, cuando jóvenes, tuvo un papel decisivo, tanto en el conocimiento que tenían sobre el género discurso que producían (en el caso, el cordel), como en la formación profesional como poeta.

Palabras Clave: Escolarización. Literacidad. Cordel. Poetas.

\section{NOTAS}

1 Apesar de utilizarmos esse termo, reconhecemos que ele apresenta algumas imprecisões conceituais, como esclarece Soares (2014). No artigo de Ferraro (2002) sobre o analfabetismo e os níveis de letramento no Brasil, o autor chama a atenção para as concepções (excludentes) que estiveram, ao longo da história, atreladas ao termo analfabeto, que, no sentido epistemológico, significa a(n)alfabeto, aquele que é privado do alfabeto, ou seja, que não sabe ler e escrever. 
2 É importante salientar que tomamos, neste artigo, o termo "escolaridade" como o processo educativo ocorrido na instituição escolar.

3 Os almocreves eram pessoas que trabalhavam conduzindo animais de carga ou mercadorias de um lugar a outro.

4 Os almocreves eram pessoas que trabalhavam conduzindo animais de carga ou mercadorias de um lugar a outro.

5 Não podemos desconsiderar que determinadas semelhanças entre esses poetas são decorrentes das experiências sociais e vivências comuns que compartilham, especialmente por pertencerem a um mesmo grupo geracional.

\section{REFERÊNCIAS}

ABREU, M. A. de. “Então se forma a história bonita” - relações entre folhetos de cordel e literatura erudita. Horizontes Antropológicos, Porto Alegre, v. 10, n. 22, p. 199-218, 2004. Disponível em: <http://www.scielo.br/pdf/ha/v10n22/22701.pdf>. Acesso em: 7 maio. 2016.

Entre a oralidade e a escrita: um estudo dos folhetos de cordel nordestinos. E.L.O. Faro, v.1, n. 3, 1997. Disponível em: <https://sapientia.ualg.pt/bitstream/10400.1/1416/1/Abreu.pdf>. Acesso em: 8 maio 2016.

. Histórias de cordéis e folhetos. 2. ed. São Paulo: Mercado das Letras, 2006.

. Cordel português e folhetos nordestinos: confrontos um estudo histórico-comparativo. 1993. 360f. Tese (Doutorado Literatura Comparada) - Programa de Pós-graduação em Teoria Literária, Campinas, 1993.

AMORIM, M. A. Existe um novo cordel? Imaginário, tradição e cibercultura. Cibertextualidades, Porto, n.3, p. 59-71, 2009. Disponível em: <http://bdigital.ufp.pt/bitstream/10284/1358/1/cibertxt_3_p59-71_amorim.pdf>. Acesso em: 13 jun. 2017.

ANUÁRIO ESTATÍSTICO DO BRASIL 1948. Rio de Janeiro: IBGE, v. 9, 1949. Disponível em: <https://seculoxx.ibge.gov.br/images/seculoxx/arquivos_download/educacao/1948/ educacao1948m_ae b_47a48.pdf> Acesso em: 14 jun.2017.

ARANTES, A. A. O trabalho e a fala: estudo antropológico sobre os folhetos de cordel. São Paulo: Editora Kairós/FUNCAMP, 1982.

AYALA, M. I. N. Abc, folheto, romance ou verso: a literatura impressa que se quer oral. Graphos, João Pessoa, v. 12, n. 2, dez. 2010.

BARDIN, L. Análise de conteúdo. Tradução de Luís Antero Reto e Augusto Pinheiro. Lisboa: Edições, 1979.

FRADE, I. C. A. da S. Método alfabético e de soletração. In: CEALE, Glossário. Termos de alfabetização, leitura e escrita para educadores. Belo Horizonte: FaE, 2014. Disponível em: 
<http://ceale.fae.ufmg.br/app/webroot/glossarioceale/verbetes/metodo-alfabetico-e-de-soletracao>. Acesso em: 12 jul. 2017.

FERRARO, A. R. Analfabetismo e níveis de letramento no Brasil: o que dizem os censos? Educação e Sociedade, Campinas. v. 23, n. 81, p. 21-47, 2002.

GALVÃO, A. M. de O. Cordel: leitores e ouvintes. Belo Horizonte: Autêntica, 2006. Ler/ouvir folhetos de cordel em Pernambuco: 1930-1950. 2000. 537f. Tese (Doutorado em Educação) - Programa de Pós-graduação em Educação, Universidade Federal de Minas Gerais, Belo Horizonte, 2000.

. Oralidade, memorização e a mediação do outro: práticas de letramento entre sujeitos com baixos níveis de escolarização: o caso do cordel (1930-1950). Educação e Sociedade, Campinas, v. 23, n.81, p. 115-142, 2002.

. Processos de inserção de analfabetos e semi-alfabetizados no mundo da cultura escrita (1930-1950). Revista Brasileira de Educação, Rio de Janeiro, v. 16, p. 81-94, 2001.

;BATISTA, A. A. G. A leitura na escola primária brasileira. Presença Pedagógica, Belo Horizonte, n. 24, v. 4, p. 20-29, nov./dez. 1998.

KLEIMAN, A. Os significados do letramento: uma nova perspectiva sobre a prática social da escrita. Campinas: Mercado da Letras, 1995.

LAVILLE, C.; DIONNE, J. A construção do saber; manual de metodologia da pesquisa em ciências humanas. Porto Alegre: Artmed, 1999.

MATOS, E. Literatura de cordel: a escuta de uma voz poética. Revista Cultura Crítica, São Paulo, p. 8-14, 2007.

MINAYO, M. C.; SANCHES, O. Quantitativo-qualitativo: oposição ou complementaridade? Caderno de Saúde Pública, Rio de Janeiro, v. 9, n. 3, p. 239-262, jul./set. 1993.

MORAES, A. D. J.; SANTOS, S. M. Escolas rurais: saberes e práticas de alfabetização (1931-1961). In: SEMINÁRIO NACIONAL DE ESTUDOS E PESQUISAS, 8., 2009, Campinas. Anais... Campinas: UNICAMP, 2009.

MORTATTI, M. do R. Educação e letramento. São Paulo: Editora UNESP, 2004.

História dos métodos de alfabetização no Brasil. In: Seminário "Alfabetização e letramento em debate". Brasília: Departamento de Políticas de Educação Infantil e Ensino Fundamental da Secretaria de Educação Básica do Ministério da Educação, 2006.V.1.p.1-14. Disponível em: <http://portal.mec.gov.br/seb/arquivos/pdf/Ensfund/ alf_mortattihisttextalfbbr.pdf $>$. Acesso em: 15 out. 2013.

OLIVEIRA, V. de S. Á. Um estudo de caso de letramento literário em família de camadas populares. 2015, 287 f. Tese (Doutorado) - Programa de Pós-Graduação em Educação, Faculdade de Educação, Universidade Federal de Minas Gerais, Belo Horizonte, 2015. 
RESENDE, V. de M. Literatura de cordel no Brasil: transformações nas práticas discursiva e social. Revista Intercâmbio dos Congressos Internacionais de Humanidades (UnB), v. 1, p. 1-7, 2010.

SAUTCHUK, J. M. M. A poética do improviso: prática e habilidade no repente nordestino. 2009. 222 f. Tese (Doutorado em Antropologia) - Programa de Pós-graduação em Antropologia Social, Universidade de Brasília, Brasília, 2009.

SILVA, M. do S. Diretrizes operacionais para a escola do campo: rompendo o silêncio das políticas educacionais. In: BATISTA, F. M.; BATISTA, N. de Q. (Org.). Educação rural: sustentabilidade do campo. Feira de Santana, BA: MOC/UEFS, 2003. p. 28-51.

SOARES, M. B. Letramento: um tema em três gêneros. 3. ed. Belo Horizonte: Autêntica, 2009.

Novas práticas de leitura e escrita: letramento na cibercultura. Educação e Sociedade, Campinas, v. 23, n. 81, p. 143-160, dez. 2002.

. Alfabetização e letramento. São Paulo: Contexto, 2014.

STREET, B. Letramentos Sociais: abordagens críticas do letramento no desenvolvimento, na etnografia e na educação. Tradução Marcos Bagno. São Paulo: Parábola Editorial, 2014.

TERRA, R. B. L. Memórias de lutas: literatura de folhetos do Nordeste 1893-1930. São Paulo: Global, 1983.

July Rianna Melo: Graduada em Pedagogia (2015) e mestra em Educação (2017), pela Universidade Federal de Pernambuco, doravante UFPE. Tem experiência na área de Educação, concentrando-se, principalmente, no estudo de temas relativos à alfabetização $e$ ao letramento. É, atualmente, pedagoga do do Centro Acadêmico do Agreste da Universidade Federal de Pernambuco.

E-mail: july.rianna@hotmail.com

AleXSANDRO Silva: Graduado em Pedagogia (2000), mestre (2003) e doutor (2008) em Educação pela Universidade Federal de Pernambuco (UFPE), com período sanduíche no Institut National de Recherche Pédagogique (INRP) - Paris (2007). É também pós-doutor, na área de Didática da Língua, pela Université Sorbonne-Nouvelle - Paris 3 - Paris (2015-1016). Atualmente, é Professor Associado 1 do Centro Acadêmico do Agreste da Universidade Federal de Pernambuco, onde atua no curso de graduação em Pedagogia e no Programa de Pós-Graduação em Educação Contemporânea. É também docente do 
Programa de Pós-Graduação em Educação do Centro de Educação e membro do Centro de Estudos em Educação e Linguagem (CEEL) da mesma universidade. Participa dos grupos de pesquisa Didática da Língua Portuguesa, Práticas de Leitura e Escrita na Educação Infantil, ambos da UFPE, e Tecnologias, Culturas e Linguagens, da UEPB.. Tem experiência na área de Educação, dedicando-se, principalmente, ao estudo de temas relativos ao ensino e à aprendizagem da língua portuguesa, como alfabetização, leitura, escrita e reflexão sobre a língua.

E-mail: alexs-silva@uol.com.br 